Article

\title{
Transport-Based Social Exclusion in Rural Japan: A Case Study on Schooling Trips of High School Students
}

\author{
David Perez-Barbosa * and Junyi Zhang \\ Graduate School for International Development and Cooperation, Hiroshima University, Higashi-Hiroshima 739-8529, Japan; \\ E-Mails: barbosad@hiroshima-u.ac.jp (D.P.-B.), zjy@hiroshima-u.ac.jp (J.Z.) \\ * Corresponding author
}

Submitted: 27 June 2017 | Accepted: 20 September 2017 | Published: 28 December 2017

\begin{abstract}
The well-being of young people-particularly aspects such as physical and mental health-has become an increasing concern for Japan's government due, in part, to the aging and declining depopulation that Japan has been experiencing in recent years. Considering this, a survey of well-being and travel-to-school behavior was carried out in four high schools of Hiroshima Prefecture, Japan; between May and September 2016 with 1,017 valid samples. The respondents' ages vary between 15 and 19 years old. We argue that transport-based social exclusion results from not only situations of transport disadvantage, but also reduced or deteriorated individual well-being. Here, well-being is measured by using constructs grouped into three main categories: happiness, healthy lifestyle propensity, and social exclusion. We found the following potential issues of transport-based social exclusion: residents in depopulating areas experience lower levels of well-being than people in non-depopulating areas. Travel times longer than 30 minutes have negative effects on happiness, traffic safety perception, health conditions, and personal health habits. Bicycle users tend to experience higher levels of wellbeing in general, whereas bus and car users tend to experience less in comparison. Special attention should be paid to improving affordability and flexibility of bus services for students.
\end{abstract}

\section{Keywords}

depopulation; high school; Japan; rural area; social exclusion; student; transport; well-being

\section{Issue}

This article is part of the issue "Regional and Urban Mobility: Contribution to Social Inclusion", edited by Janet Stanley (University of Melbourne, Australia) and John Stanley (University of Sydney, Australia).

(C) 2017 by the authors; licensee Cogitatio (Lisbon, Portugal). This article is licensed under a Creative Commons Attribution 4.0 International License (CC BY).

\section{Introduction}

In Japan, students' commute to school has certain particularities in comparison to other (mainly western) countries. Children are expected to make the journey on their own starting in the first grade of elementary school (CBS News, 2015) and, in addition, schools commonly discourage parents from dropping children off by car and even cycling to school in a few cases (Kidd, 2013).

In elementary school, the trip to school is mostly within walking distance, and in fact it is quite common to hear of students who walk to school every day, despite a fairly long distance from home (NILS, 2017). Par- ticularly in urban areas, there are several schools within walking distance for children, although the districts and distances to and from school are decided based on the local characteristics of each municipality (Mori, Armada, \& Willcox, 2012).

In the Tokyo metropolitan area, it has been estimated that the walk to school likely takes less than $20 \mathrm{~min}$ utes for a child attending a public elementary school (Kawano, 2016). Nevertheless, the daily home-school trip is likely to become longer once children enter high schools. In large urban areas, taking public transportation for a 2-hour commute to school is not uncommon for children (Guo, 2013; Johnson \& Johnson, 1996). Tagaya 
et al. (2004) find average times of 75.5 minutes and Honda, Genba, Kawakami and Nishizono-Maher (2008) find average times of 55 minutes for schooling trips, respectively, which is considered to be longer than the average home-school trip time of public high school students in the Tokyo metropolitan area. In addition, after junior high school, students attend schools based on standardized high school entrance examination scores. Thus, some students may have to travel great distances in order to attend the school which was determined by their test scores (Johnson \& Johnson, 1996). In addition, Japanese high school students do not drive cars (Johnson \& Johnson, 1996) and the car is still chosen by a very small percentage of students (6\%) for their daily commuting (Japan Guide, 2000).

A large number of rural areas in Japan are currently facing serious depopulation issues. Consequently, maintaining public transport in depopulating areas has become increasingly difficult. With this in mind, there is still little understanding regarding how this affects the wellbeing of students in rural areas. In order to fill the gap in existing studies, in this paper we aim to understand, in greater detail, the home-school travel behavior in rural areas of Japan from the perspective of well-being and social exclusion and discuss the implications of the analysis results. Hence, our research questions can be summarized as follows: 1) are residents in rural (depopulating) areas experiencing lower well-being than residents in urban areas? 2) If so, are these differences attributable to a poorer accessibility or provision of public transport services?

\section{Literature Review}

In this section, we review literature related to the concepts of transport disadvantage and social exclusion both separately and combined. We also explore how these issues are reflected in young Japanese who travel to school, our population group of interest.

\subsection{Links between Transport Disadvantage and Social Exclusion}

Transport has been identified as a key factor in the economic and social development process as it facilitates the movement of people and goods, thereby promoting trade and "better standards of living through improved access to markets, employment, health, education and social services" (Lucas, 2011, p. 1321).

Transport disadvantage has been commented by Schwanen et al. (2015, p. 126) as "a relational and dynamic outcome of a lack of access to basic resources, activities and opportunities for interaction...and of a lack of influence on decision-making in the context of transport policy and governance". Although transport disadvantage and its links to social exclusion has been a theme of much recent work, this relationship has not been explored across different geographic contexts (Delbosc \& Currie, 2011). Furthermore, transport disadvantage can be both absolute and relative, and it occurs at both individual and collective levels (Schwanen et al., 2015). Herwangi, Pradono, Syabri and Kustiwan (2015) argue that the study of transport disadvantage can be grouped into studies related to marginalized people, the condition of a particular area, and the implementation of transport policy in general. Additionally, mobility-related exclusion has been defined as:

The process by which people are prevented from participating in the economic, political and social life of the community because of reduced accessibility to opportunities, services and social networks, due in whole or in part to insufficient mobility in a society and environment built around the assumption of high mobility. (Kenyon, Lyons, \& Rafferty, 2002, pp. 120-121)

It has also been considered that in outer-urban areas transport disadvantage is the result of a range of intersecting factors including poor public transport infrastructure, a higher proportion of low-income households, and the need to travel further distances in order to get to places of employment, services, and activities (Rosier \& McDonald, 2011), including the quality and conditions of education in remote and isolated areas (NIER, 2012). Moreover, the built environment only has indirect effects on (travel) satisfaction through influencing commuting characteristics (Ye \& Titheridge, 2017). Therefore, it is likely that transport disadvantage will have a greater impact on social exclusion and well-being in remote areas than in (more) accessible urban areas (Delbosc \& Currie, 2011). Nevertheless, transport disadvantage and transport-related social exclusion are not necessarily synonymous with each other (Lucas, 2012).

\subsection{Social Exclusion and Life-Related Issues for Young People in Rural Japan}

In isolated (i.e., rural and mountainous) areas of Japan, school buildings and equipment are generally poor, cultural and traffic conditions are at a disadvantage and the quality of education offered there can hardly be compared to that in urban areas. For these reasons, the Japanese government has been sustaining efforts to reduce the disparities in education between isolated and non-isolated areas (NIER, 2012).

The study of social exclusion issues contributes to a better understanding of the nature and extension of these disparities that negatively affect young people's well-being. Abe $(2010,2012)$ recognizes 8 dimensions of social exclusion that are reflected in the Japanese context: lack of basic needs, material deprivation, exclusion from systems, lack of activities, housing deprivation, lack of social relations (social capital), subjective poverty and income poverty.

Some of these social exclusion issues that specifically affect young people have become of interest for researchers in recent years. Mental health issues such as 
depression have become prevalent and there is interest from government and institutions in preventing them by targeting behaviors promoting health, acquisition of social support, and high self-esteem, etc. (Takakura \& Sakihara, 2001).

Vocational high school students and upper graders were strongly associated with accumulation of healthrisk behaviors such as cigarette smoking, alcohol use and sexual intercourse clustered. (Takakura, Nagayama, Sakihara, \& Willcox, 2001). In addition, issues related to those health practices and social support were negatively related to present and persistent depressive symptoms (Takakura \& Sakihara, 2001).

\subsection{High School Students and Travel to School Issues}

Remarkably increasing attention has recently been paid to youth-related issues by more and more researchers in various disciplines, such as education, social science, psychology, health, medical science, etc. (Zhang, Chikaraishi, Xiong, Jiang, \& Seya, 2016). Some studies have recently focused on understanding young people's behavior (Takakura et al., 2001; Takakura \& Sakihara, 2001; Ichikawa \& Nakahara, 2007) by addressing high school students'-related issues more specifically. On a global scale, a variety of studies have covered topics related to the benefits of active travel to school (Broberg \& Sarjala, 2015; Mackett \& Paskins, 2008; Pont, Ziviani, Wadley, \& Abbott, 2011; Timperio et al., 2006; Trapp et al., 2011), and the importance of promoting modal shift for school trips (Hodgson, Namdeo, Araujo-Soares, \& Pless-Mulloli, 2012; Murtagh, Rowe, Elliott, McMinn, \& Nelson, 2012; Oglivie, Egan, Hamilton, \& Petticrew, 2004).

The effects of long commutes on well-being have been largely discussed, with unclear or contradictory results. Since the journey from home to work (school in our case) and back is an important aspect of modern life, it affects people's well-being and demands difficult decisions (Stutzer \& Frey, 2008). For instance, Tagaya et al. (2004) found that commuting duration influences the waking time and sleep duration of adolescents, whereas long commuting duration is the environmental factor that showed strongest association with short sleep duration. On the other hand, other studies do not find a clear relationship between school-home commuting time and total sleep time for Japanese high school students (Honda et al., 2008).

Among school teachers in Tokyo, findings have revealed that long-time commuters were more likely to sleep less, exercise less, and work less time, leading to the recognition that strategies are required to improve the healthy lifestyle for long-time commuters (Nomoto, Hara, \& Kikuchi, 2015). It was also pointed out that, while some students sleep or study during their long commute, public transportation also provides a chance for socializing with peers (Johnson \& Johnson, 1996).

Moreover, different travel modes provide travelers with specific situations that involve different levels of physical activation and exposure to social interaction (De Vos, Schwanen, Van Acker, \& Witlox, 2015). As previously mentioned, walking to school is a common practice in Japan. Although walking to school was not originally intended as an intervention to promote physical activity, unintended positive health outcomes from this practice can be observed, such as maintaining one of the lowest prevalence of childhood obesity in the world, a policy that likely benefits schoolchildren in terms of their levels of physical activity (Mori et al., 2012).

\section{Methods}

This section focuses on describing how the data for this empirical study were collected, as well as a description of the information that has been collected.

\subsection{Data Collection}

Surveys were conducted in four different locations (i.e., high schools) of Hiroshima Prefecture, Japan. The red and pink areas of the map in Figure 1 depict which municipalities in Hiroshima Prefecture have been recognized by the national government as "depopulating". Three schools are located in depopulating areas of the prefecture: Chiyoda (137 respondents), Yoshida (296 respondents) and Mukaihara (151 respondents); whereas Kamo high school is located in Higashi-Hiroshima city (433 respondents), which corresponds to a non-depopulating area.

The high schools who agreed to cooperate with our survey distributed the questionnaire and the instructions among their first, second and third grade students respectively. The age for students in high school is between 15 and 19 years old. The questionnaire included questions regarding the daily trip to school, well-being, and specific social exclusion aspects of interest (PerezBarbosa \& Zhang, forthcoming).

In Table 1, the population in the locations of study in 2011 and 2017, as well as the population density in 2017, can be observed, according to information from the respective municipal governments. In our locations, all the depopulating areas have a low population density. It should be noted that in the most densely populated area, population is still growing while in the least densely populated areas the population is decreasing.

\subsection{Measures of Transport Disadvantage and Transport-based Social Exclusion}

Generally, high-school students in rural areas of Japan must usually travel longer distances in order to get to their respective institutions than their urban peers. Additionally, the distance to facilities such as a train station, a bus stop, a medical institution or a post office have been included as criteria to calculate the degree of remoteness and isolation of the schools in mountainous areas in Japan (NIER, 2012). These types of issues are considered 


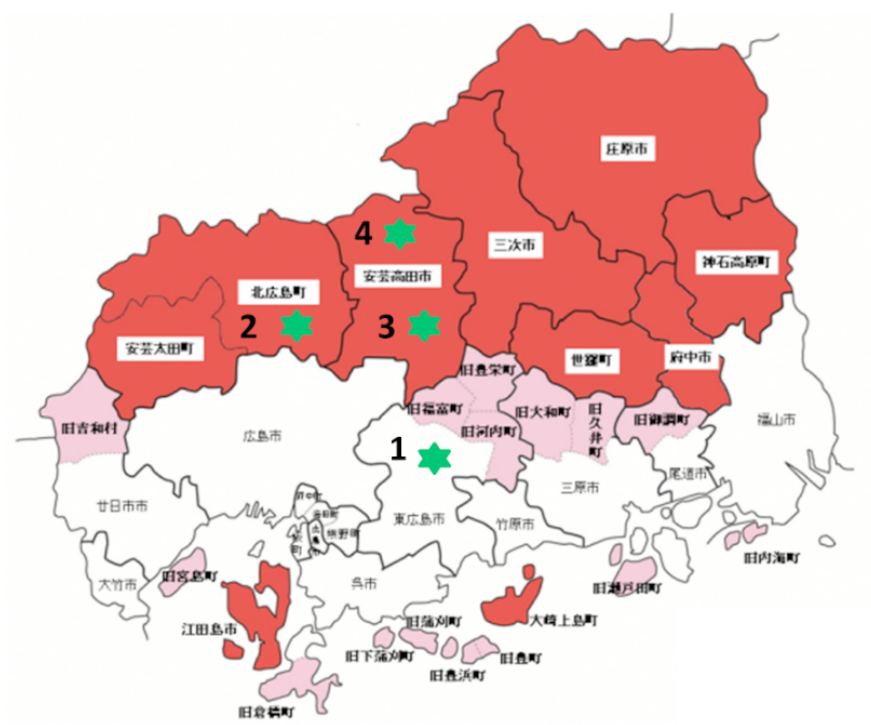

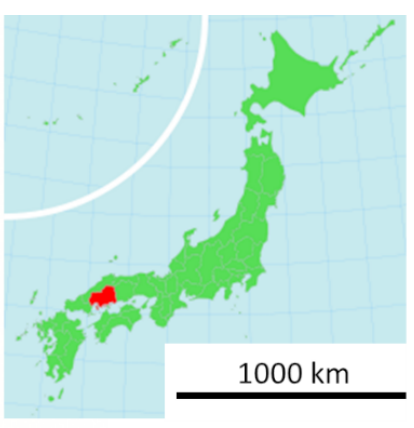

1. Kamo (Higashi-Hiroshima)

2. Chiyoda (Kita-Hiroshima)

3. Mukaihara (Akitakata)

4. Yoshida (Akitakata)

Figure 1. Locations of the survey in Hiroshima prefecture. Original images adapted from Hiroshima Prefectural Government.

Table 1. Socio-demographic information of the locations of study.

\begin{tabular}{lllll}
\hline School & 1. Kamo-Saijo & 2. Chiyoda & 3. Muhaikara & 4. Yoshida \\
\hline City/Municipality & Higashi-Hiroshima & Kita-Hiroshima & Akitakata & Akitakata \\
\hline Population - 2011 & 178,827 & 20,136 & 31,565 & 31,565 \\
Population - 2017 & 185,857 & 19,126 & 29,425 & 29,425 \\
Density - 2017 (inhab./ $\mathrm{km}^{2}$ ) & 291.85 & 30 & 59 & 59 \\
\hline
\end{tabular}

transport disadvantage. If there are negative impacts on well-being that are, to any extent, attributable to a condition of transport-disadvantage, we may reasonably argue the existence of transport-based social exclusion, assuming that for an individual, higher levels of well-being are linked to lower levels of social exclusion and vice versa. De Vos, Schwanen, Van Acker and Witlox (2013) acknowledge that as travel options differ between different kinds of neighborhoods, this can result in different levels of subjective well-being. Considering this, in this section we explain how transport disadvantage and well-being are being characterized and measured (see Figure 2).

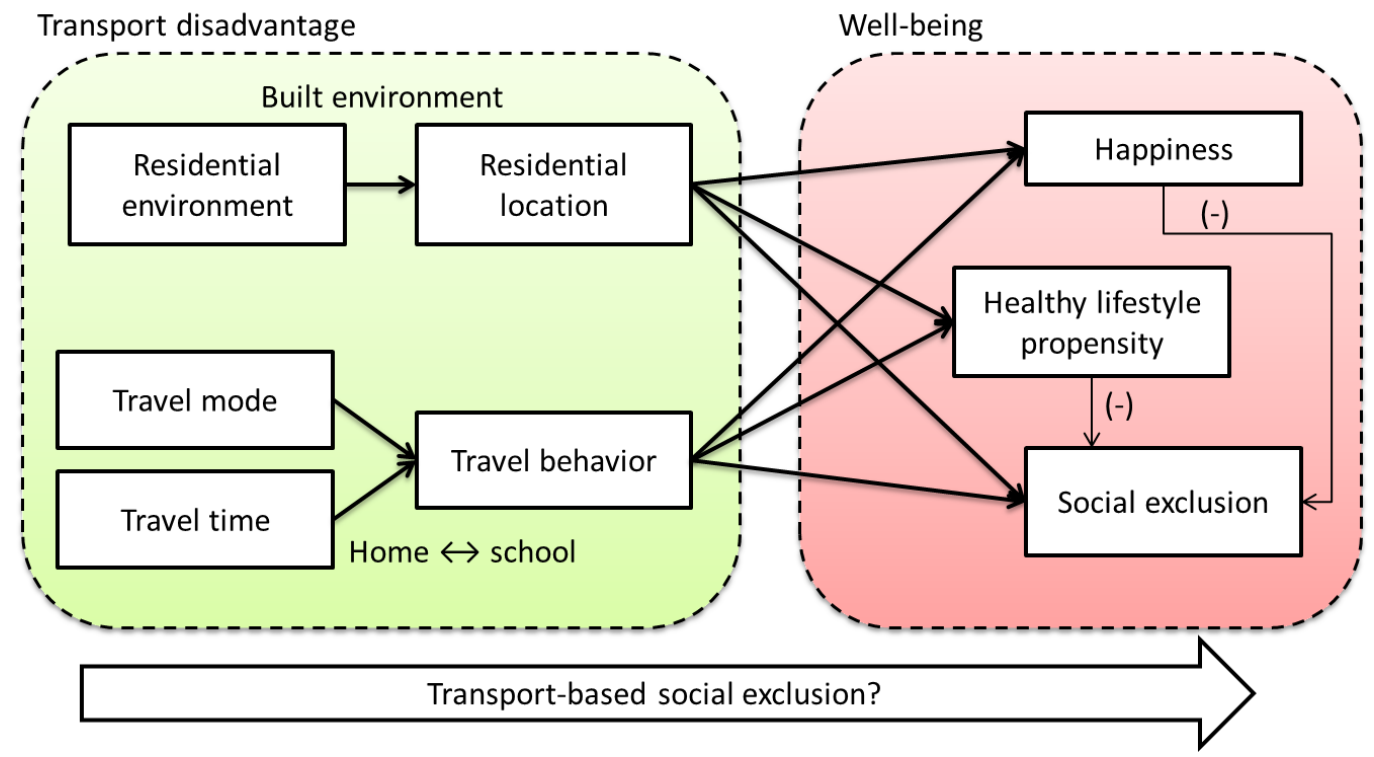

Figure 2. Conceptual framework of transport-based social exclusion. 


\subsubsection{Transport Disadvantage}

Some conditions of transport disadvantage are already an inherent part of the targeted group (i.e., high school students), such as the inability to drive to school by themselves. Thus, they must rely on non-motorized modes (walking, bicycle), public transport (bus, train), or being driven, for their daily trip to school. Considering this, we include the effects of two main types of transport disadvantage: one related to residential location and the other to travel behavior (schooling).

- Residential location: geography and the environment have a much larger influence on well-being than previously thought (Brereton, Clinch, \& Ferreira, 2008). For comparison purposes, two types of residential location will be considered: depopulating areas and non-depopulating areas respectively. We assume that residents in the former experience more disadvantages than residents in the latter, examining aspects such as the need to travel further distances to access most of the urban facilities and school itself, as well as a more reduced accessibility by public transport.

- Travel behavior: Students in the questionnaire survey were asked to describe how their daily-or most frequent-trip to school is by indicating the different travel modes they use and the duration for each of the stages in their schooling trip (see Figure 3).

\subsubsection{Well-Being}

One aim of transportation policies should be to contribute to people's subjective well-being, albeit it has received limited attention in the transport research and planning communities (Ettema, Gärling, Olsson, \& Friman, 2010). Although the question of how wellbeing should be defined still remains largely unanswered (Dodge, Daly, Huyton, \& Sanders, 2012), we pay special attention to issues such as acceptable quality of life and good health regarding its physical, mental and social dimensions. As such, well-being is assessed in terms of three main aspects: happiness (with several life domains), healthy lifestyle propensity, and social exclusion. The question items for each aspect were selected based on careful literature review, and can be observed in greater detail in Table 2.

\section{Results}

\subsection{Travel Behavior}

Based on the individual descriptions of travel to school, for each trip the dominant mode is considered as the main travel mode to school. The modal share for each school can be observed in Figure 4. With exception of Mukaihara High School (where the predominant travel mode is train by a large proportion, due also to a mountainous topography and its proximity to Hiroshima City), the most common travel mode to school is by bicycle. Long-distance travels that require the combined use of two or more modes are relatively uncommon. It should be noted that only Mukaihara and Kamo high schools can be accessed by railway. In contrast, for the locations Chiyoda and Yoshida, which are in more isolated areas, a larger dependence on buses and cars can be noted.

In Table 3, the average travel time to school by main travel mode(s) can be observed. The main travel mode(s) is the one (or the combination of two or more) used to cover the longest portion of the trip to school. It should be noted that the shortest average travel times are for non-motorized modes, while all the average travel times exceed 40 minutes for public transport users. For example, according to the example in Figure 3 , the corresponding main modes would be bus and train combined.

\subsection{Residential Location and Built Environment}

The built environment is characterized by the distance from home to the nearest urban facilities that are listed in Table 4. With exception of post office, hospitals, police station, kindergarten and game centers, there are significant statistical differences between the distance from home to facilities in depopulating (rural) areas and non-depopulating (sub-urban) areas.
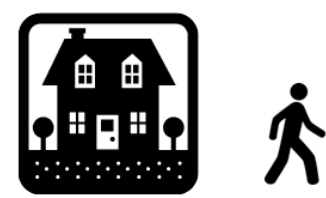

Leave $\quad$ Walk
home

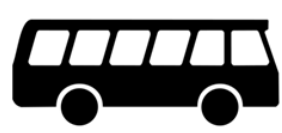

Take a Bus

25 mins

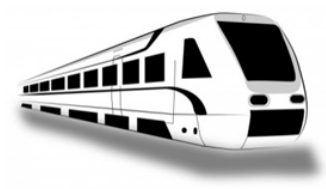

Ride a train 15 mins

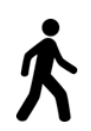

Walk to school 10 mins

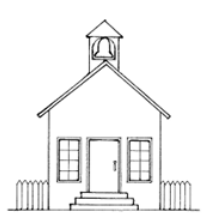

Arrive to school

Total travel time: 55 mins

Figure 3. Example of a description of a daily travel to school. 
Table 2. Measurements of well-being.

\begin{tabular}{|c|c|}
\hline Well-being aspects & Related indicators \\
\hline $\begin{array}{l}\text { Happiness: "How happy } \\
\text { do you feel } \\
\text { with your...?" }\end{array}$ & $\begin{array}{l}\text { Family finances, health, your family's health, relations with your neighbors, relations in other } \\
\text { social networks, education, family life, leisure and social life, standard of living, what you are } \\
\text { achieving in life, current safety, future safety, spirituality/religion, life as a whole. }\end{array}$ \\
\hline $\begin{array}{l}\text { Healthy lifestyle } \\
\text { propensity: "How } \\
\text { important is it for } \\
\text { you to...?" }\end{array}$ & $\begin{array}{l}\text { Eat breakfast every morning (LH1), Get enough sleep (LH2), Eat balanced and healthy food } \\
\text { (LH3), Not smoke (LH4), Do physical activity (LH5); Living in a peaceful environment (LH6), Go } \\
\text { to a park (LH7), Play sports (LH8), Participate in club activities (LH9), Do other social activities } \\
\text { such as volunteering (LH10), Get to know your neighbors (LH11), attend cultural facilities } \\
\text { regularly (museums, cinema, libraries) (LH12), Participate in out-of-home activities (LH13), } \\
\text { Spend time with family (LH14), Spend time/go out with friends (LH15). }\end{array}$ \\
\hline $\begin{array}{l}\text { Social exclusion: "How } \\
\text { much do you agree with } \\
\text { the following } \\
\text { statements?" }\end{array}$ & $\begin{array}{l}\text { I feel safe with the traffic in my neighborhood (SE1), I feel safe during my daily travel (SE2), } \\
\text { I feel I am in good physical health (SE3), I feel I am in good mental health (SE4), I feel in good } \\
\text { bodily shape (SE5), I can participate in community activities (SE6), I can participate in } \\
\text { community decision-Making processes (SE7), I am able to express myself as I wish (expression } \\
\text { of identity) (SE8), I like volunteering for various activities (SE9), I can often access green spaces } \\
\text { and the natural environment (SE10), I enjoy the places with a rich natural environment (SE11), } \\
\text { I like the lifestyle in my current residential area (SE12), I want to have a very different lifestyle } \\
\text { in the future (SE13), I can rely on public transport to go to the places I need (SE14), I live close } \\
\text { enough to the places I like to go frequently (SE15), My daily travel to school is affordable to me } \\
\text { and my family (SE16), I can get help from my close family when I need it (SE17), I can get help } \\
\text { from my extended family when I need it (SE18), I can get help from my friends when I need it } \\
\text { (SE19), I can get help from my neighbors when I need it (SE20), People in my community can } \\
\text { get support from the local government for some of their daily life difficulties (SE21). }\end{array}$ \\
\hline
\end{tabular}

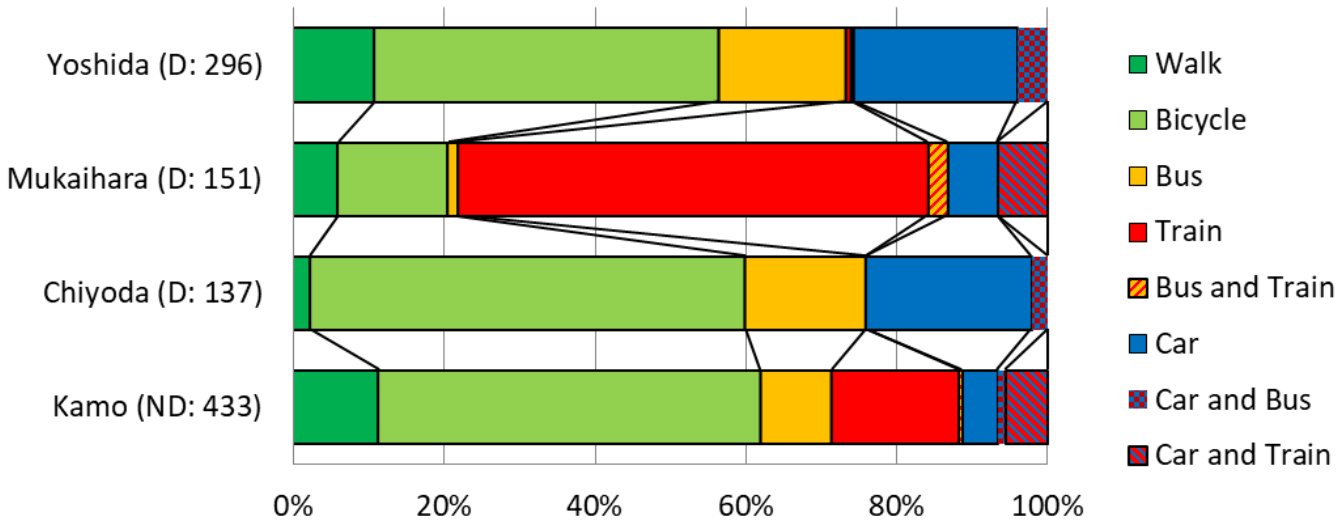

Figure 4. Main travel mode to school. Notes: (D): Depopulating area, (ND): Non-depopulating area. Numbers in parentheses indicate the number of valid sample answers collected in each school.

Table 3. Average travel time to school by main travel mode(s).

\begin{tabular}{lllllllll}
\hline Main travel mode & Walk & Bicycle & Bus & Train & Bus and Train & Car & Car and Bus & Car and Train \\
\hline Travel time & 13.1 & 19.1 & 45.6 & 48.8 & 52.9 & 21.0 & 42.4 & 38.6 \\
(Std. Dev.) & $(6.9)$ & $(10.9)$ & $(18.9)$ & $(22.0)$ & $(23.7)$ & $(11.1)$ & $(13.3)$ & $(10.7)$ \\
N & 93 & 455 & 115 & 169 & 7 & 124 & 20 & 34 \\
\hline
\end{tabular}

Notes: $\mathrm{N}$ corresponds to number of respondents by travel mode; unit of travel time: minutes.

\subsection{Well-Being Measurements}

In this section, the distribution of the well-being measurements detailed in Table 2 can be observed in Figure 5, Figure 6, and Figure 7. For comparison effects, and considering the distribution of the responses, the fol- lowing categories will be considered: for social exclusion (see Figure 5) we consider the less satisfied group (respondents who answered not at all or few times for the agreement level) and the more satisfied group (respondents who answered several times and totally agree); for healthy propensity lifestyle, we consider the portion 
Table 4. Distance from home to different urban facilities.

\begin{tabular}{|c|c|c|c|c|c|c|c|}
\hline & \multicolumn{2}{|c|}{ Depopulating area (584) } & \multicolumn{2}{|c|}{ Non-depopulating area (433) } & \multicolumn{2}{|c|}{ ANOVA Test } & \\
\hline & Dist. & (SD) & Dist. & (SD) & F-value & $p$-value & \\
\hline School & 9.6 & (8.8) & 7.0 & $(7.5)$ & 25.1 & $<0.001$ & $* * *$ \\
\hline Bank/post office & 3.3 & (7.2) & 4.0 & (9.7) & 2.0 & 0.160 & \\
\hline Convenience store & 3.1 & (6.4) & 1.5 & $(4.5)$ & 19.5 & $<0.001$ & $* * *$ \\
\hline Supermarket & 4.4 & (7.9) & 2.3 & $(5.0)$ & 24.6 & $<0.001$ & $* * *$ \\
\hline Drugstore & 8.0 & $(11.5)$ & 4.6 & $(10.2)$ & 24.0 & $<0.001$ & $* * *$ \\
\hline Train station & 12.9 & (14.4) & 5.0 & $(8.3)$ & 105.3 & $<0.001$ & $* * *$ \\
\hline Bus stop & 2.8 & (7.9) & 3.7 & $(10.6)$ & 2.9 & 0.091 & $*$ \\
\hline Sports facilities & 8.9 & (12.6) & 10.4 & (14.4) & 3.2 & 0.074 & $*$ \\
\hline Park & 9.0 & (14.6) & 4.0 & (10.4) & 37.5 & $<0.001$ & $* * *$ \\
\hline Community center & 6.5 & $(12.3)$ & 4.2 & $(10.2)$ & 10.3 & 0.001 & $* * *$ \\
\hline Hospital/health center & 5.3 & (9.2) & 4.9 & $(10.2)$ & 0.5 & 0.497 & \\
\hline Swimming pool & 10.7 & $(13.4)$ & 17.5 & $(18.0)$ & 47.4 & $<0.001$ & $* * *$ \\
\hline Game center & 12.8 & (14.0) & 11.4 & (14.7) & 2.5 & 0.111 & \\
\hline Bowling center & 25.0 & (13.9) & 13.7 & $(14.2)$ & 110.6 & $<0.001$ & $* * *$ \\
\hline Baseball center (bating) & 23.6 & (14.7) & 18.3 & $(16.3)$ & 20.4 & $<0.001$ & $* * *$ \\
\hline Shopping center & 21.7 & (17.4) & 14.9 & (17.7) & 25.8 & $<0.001$ & $* * *$ \\
\hline Clothing shop & 10.2 & (13.4) & 8.4 & (13.4) & 4.1 & 0.042 & $* *$ \\
\hline Bookstore & 10.1 & (12.7) & 6.2 & (11.3) & 25.0 & $<0.001$ & $* * *$ \\
\hline Cram school & 12.8 & (16.4) & 5.8 & (11.6) & 56.0 & $<0.001$ & $* * *$ \\
\hline City hall & 7.4 & (11.3) & 9.0 & $(12.2)$ & 4.5 & 0.034 & $* *$ \\
\hline Police station & 5.2 & (9.3) & 5.7 & (10.3) & 0.8 & 0.369 & \\
\hline Kindergarten & 4.4 & (9.1) & 3.5 & $(8.7)$ & 2.5 & 0.118 & \\
\hline
\end{tabular}

Notes: Significant at * 90\%, ** 95\%, ${ }^{* * *} 99 \%$ level. Average distances in kilometers.

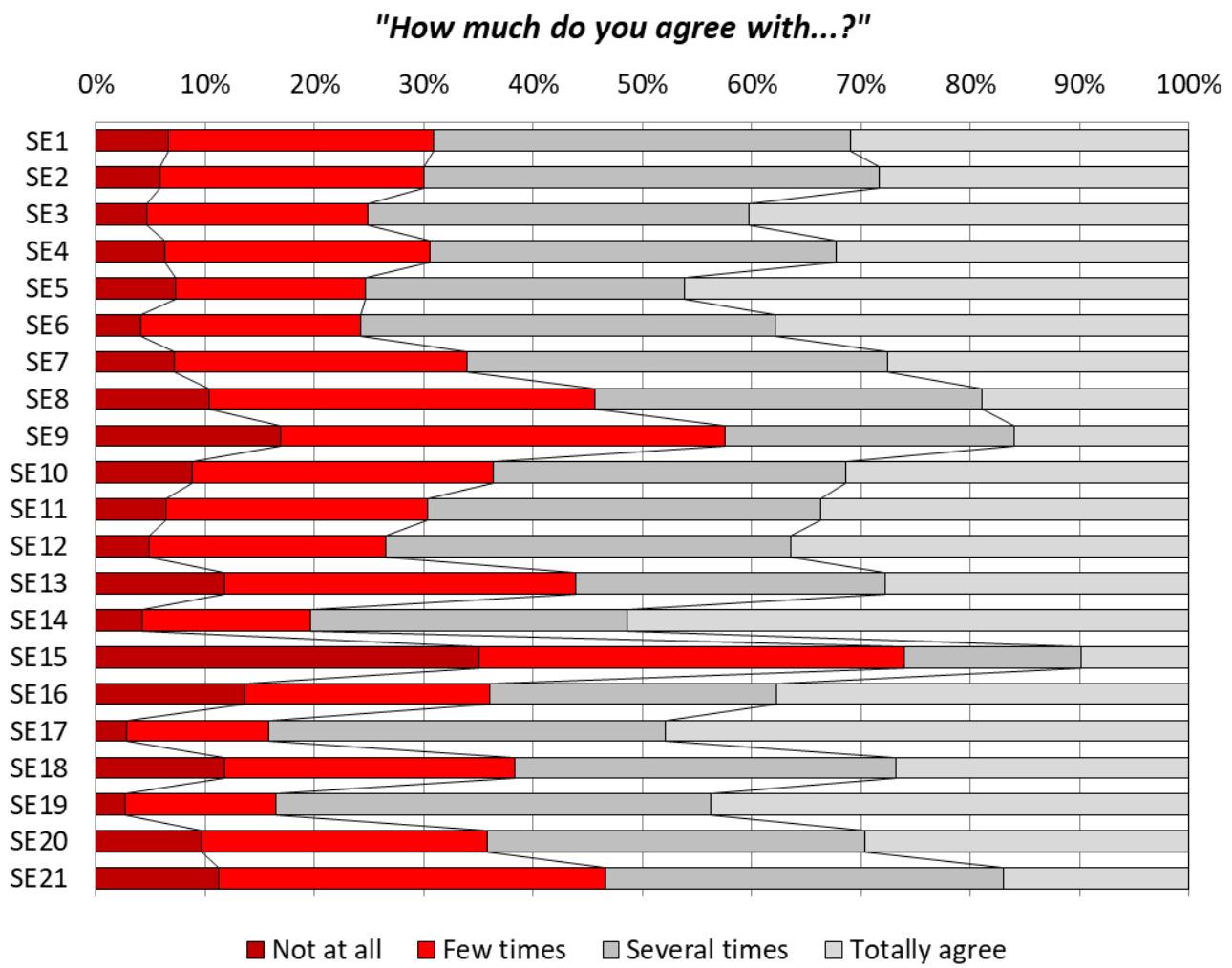

Figure 5. Measurement of social exclusion. 


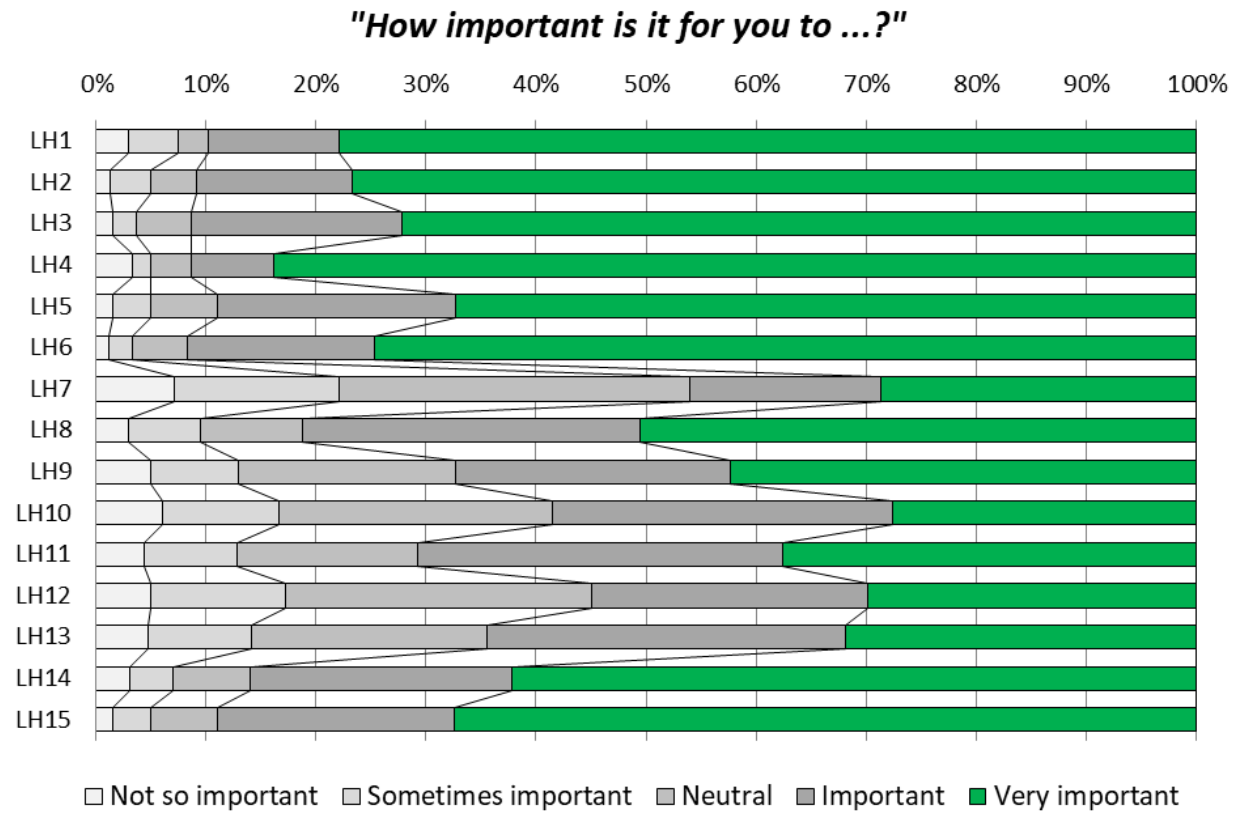

Figure 6. Importance of health habits.

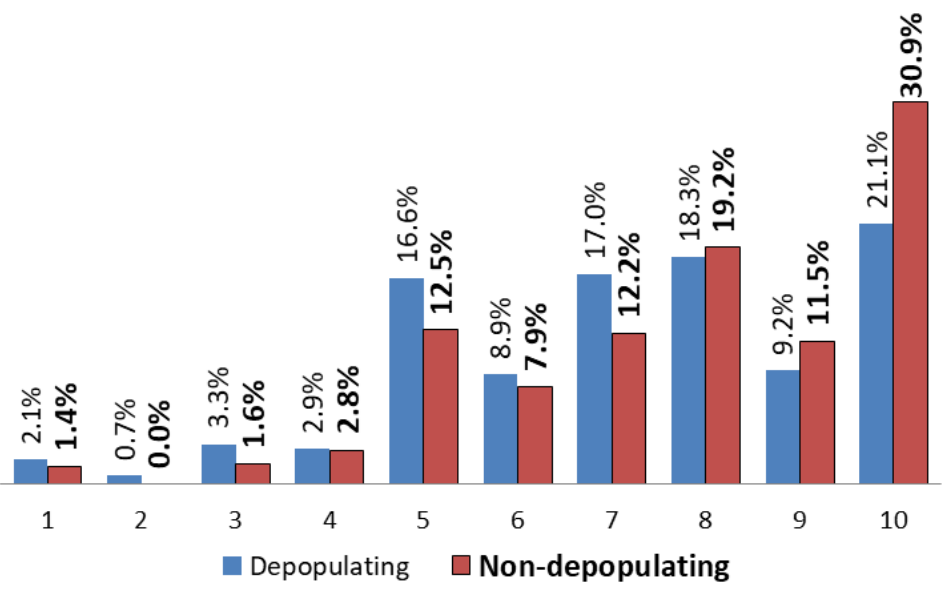

Figure 7. Distribution of happiness scores according to the type of area. Note: 1 is the most unhappy condition, 10 is the happiest condition.

of respondents who consider the practice if each of the mentioned habits very important (see Figure 6). Based on the distribution of happiness scores, we can consider three levels: low (scores from 1-4), medium (5-7) and high (8-10). In Figure 7 the difference of score distributions between depopulating and non-depopulating areas can be observed.

\section{Analysis of Transport-Based Social Exclusion Issues}

\subsection{Influence of Depopulating Area on WB}

Firstly, the variations of the different well-being indicators are compared between depopulating and nondepopulating areas.

Based on the responses for the questions related to social exclusion (SE1-SE21), we can distinguish two main groups: the first group reflects a big (or total) agreement whereas the second group reflects little (or no) agreement. Then, the percentage of individuals that agree within each type of zone (depopulating and nondepopulating) is compared, and the Pearson Chi-Squared test is employed for testing which differences are statistically significant. The results can be observed in Figure 8 and Table 5.

Regarding happiness with all the aforementioned life domains, as well as for all the aspects of healthy lifestyle propensity that were assessed, higher scores were found for non-depopulating areas in comparison with depopulating areas. However, some mixed results can be observed regarding social exclusion (see Figure 9). Additionally, we found that the social exclusion items can be grouped into seven bigger categories: safety, health, participation, nature, lifestyle, accessibility, and social support. This was 


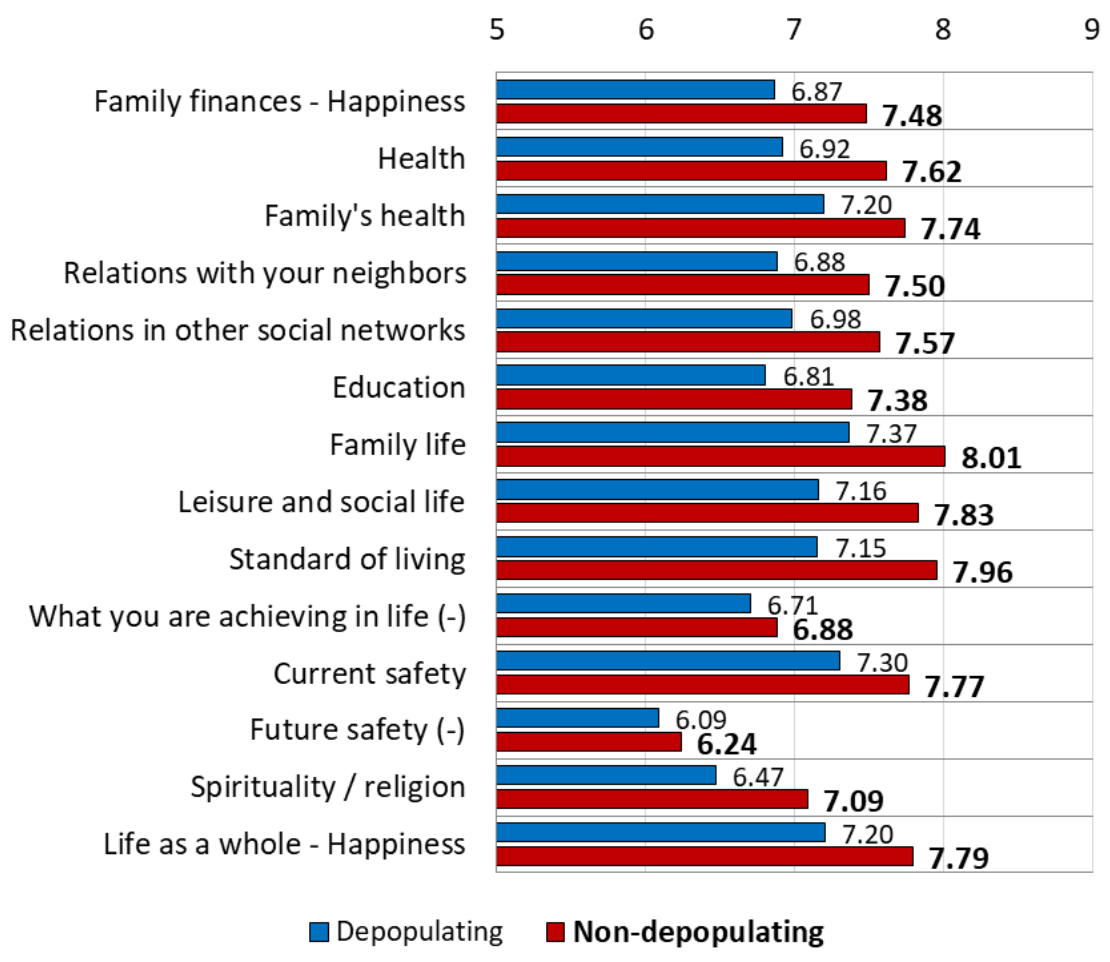

Figure 8. Average happiness scores regarding different life domains for depopulating and non-depopulating areas.

Table 5. Propensity to a healthy lifestyle: variation between types of area.

\begin{tabular}{|c|c|c|c|}
\hline \multirow[b]{2}{*}{ Lifestyle and health habits } & \multicolumn{2}{|c|}{ Type of area (a) } & \multirow{2}{*}{$\begin{array}{l}\text { Pearson- } \chi^{2(b)} \\
(\mathrm{df}=1)\end{array}$} \\
\hline & $D(433)$ & ND (584) & \\
\hline Eat breakfast every morning (LH1) & 72.4 & 85.2 & $23.60 * * *$ \\
\hline Get enough sleep (LH2) & 71.1 & 84.3 & $24.36 * * *$ \\
\hline Eat balanced and healthy food (LH3) & 64.7 & 82.2 & $37.87 * * *$ \\
\hline Not smoke (LH4) & 81.0 & 87.8 & $8.42 * * *$ \\
\hline Do physical activity (LH5) & 63.2 & 72.7 & $10.32 * * *$ \\
\hline Living in a peaceful environment (LH6) & 70.9 & 79.7 & $10.13^{* * *}$ \\
\hline Go to a park (LH7) & 26.5 & 31.4 & $2.88^{*}$ \\
\hline Play sports (LH8) & 46.2 & 56.4 & $10.18^{* * *}$ \\
\hline Participate in club activities (LH9) & 39.6 & 46.2 & $4.48 * *$ \\
\hline Other social activities (LH10) & 26.5 & 28.9 & 0.68 \\
\hline Get to know your neighbors (LH11) & 34.6 & 41.6 & $5.17^{* *}$ \\
\hline Regular access to cultural facilities (LH12) & 29.8 & 30.0 & 0.01 \\
\hline Participation is various activities (LH13) & 27.4 & 37.9 & $12.57^{* * *}$ \\
\hline Spend time with family (LH14) & 56.8 & 69.3 & $16.34 * * *$ \\
\hline Spend time/going out with friends (LH15) & 62.8 & 73.7 & $13.28 * * *$ \\
\hline
\end{tabular}

Notes: (a) Values represent the percentage of respondents within each type of area who consider the practice of each one of the listed lifestyle and health habits as very important. D: Depopulating area; ND: Non-depopulating area; ${ }^{(b)}$ Pearson Chi-square values significant at $* 90 \%, * * 95 \%, * * * 99 \%$ level.

confirmed by the results of factor analysis (Varimax rotation, $K M O=0.864,67.8 \%$ of variance explained).

For depopulating areas, higher satisfaction with a few aspects of social exclusion was found: volunteering (SE9, $\left.\chi^{2}=6.56, p=0.010\right)$, enjoyment of the natural environment (SE11, $\chi^{2}=5.12, p=0.024$ ) and change of lifestyle (SE13, $\chi^{2}=5.7, p=0.017$ ). It reflects that features associated to low density environments can contribute pos- itively to well-being. Dolan, Peasgood and White (2008) remark that more research is needed to understand the effects of social capital and contact with local community on well-being, whereas Schwanen and Wang (2014) mention that out-of-home activities tend to be more undertaken in lower density areas.

For non-depopulating areas, students show higher satisfaction regarding physical health (SE3, $\chi^{2}=13.4$, 


\section{Social exclusion - comparison between areas}

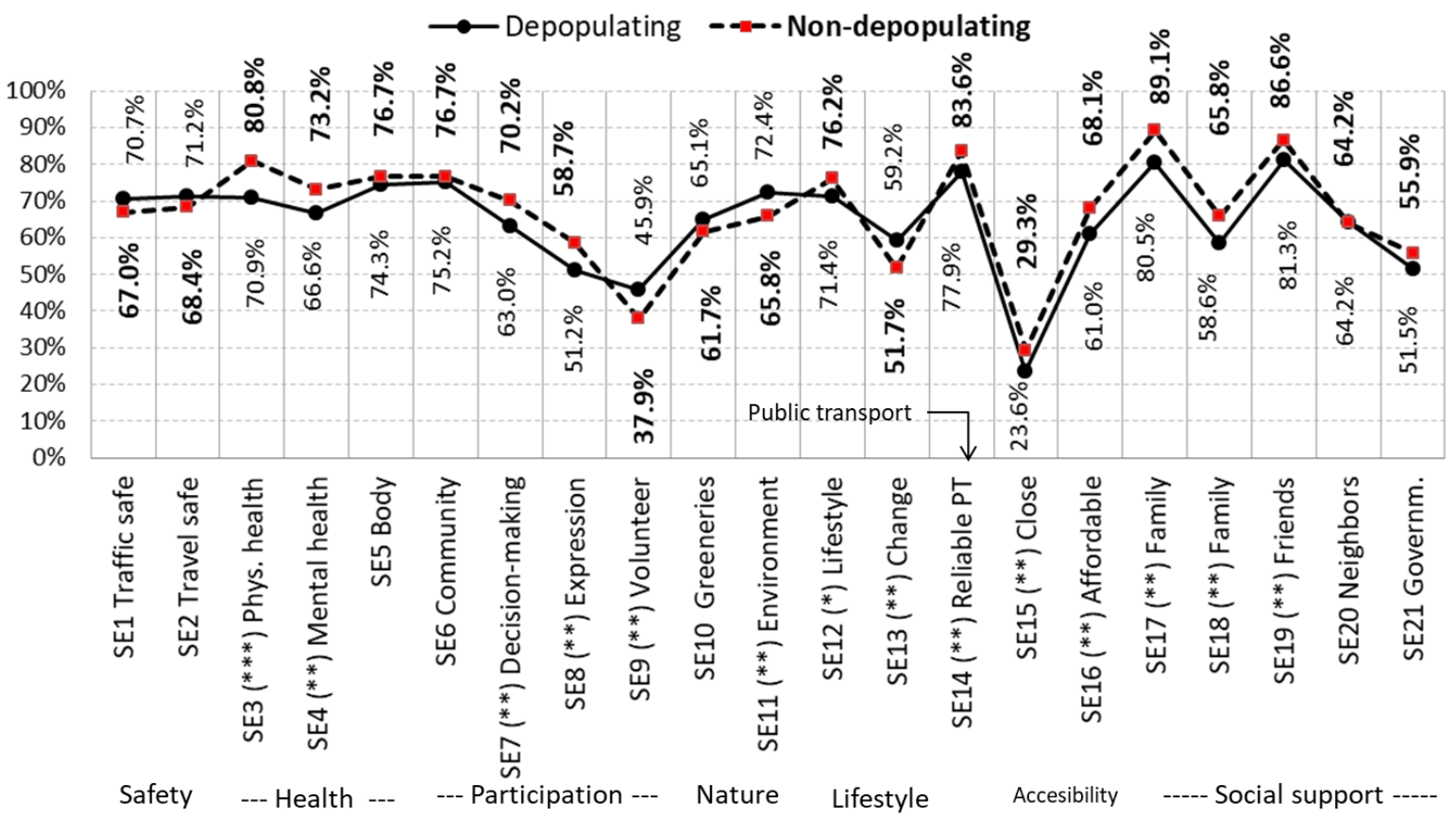

Figure 9. Comparison of social exclusion between areas.

$p<0.001)$, mental health (SE4, $\left.\chi^{2}=5.14, p=0.023\right)$, participation in community decision-making (SE7, $\chi^{2}=5.78$, $p=0.016$ ), self-expression (SE8, $\chi^{2}=5.59, p=0.018$ ), lifestyle (SE12, $\left.\chi^{2}=2.97, p=0.085\right)$, public transport reliability (SE14, $\chi^{2}=5.17, p=0.023$ ), accessibility (SE15, $\chi^{2}=4.17, p=0.041$; SE16, $\left.\chi^{2}=5.58, p=0.018\right)$, and social support from family and friends (SE17, $\chi^{2}=14.5$, $p<0.001$; SE18, $\chi^{2}=5.57, p=0.018$; SE19, $\chi^{2}=5.12$, $p=0.024)$.

For other aspects of social exclusion related issues, such as safety (SE1, SE2), obesity (SE5), participation in community activities (SE6), access to green areas and social support from neighbors and community (SE20, SE21), no significant differences were found between depopulating and non-depopulating areas.

\subsection{Influence of Travel Behavior on Well-Being}

The average happiness by travel mode and the correlation values between travel time in minutes (total and by mode) and the happiness values can be observed in Table 6. Although, in general, happiness increases as travel time decreases (Morris \& Guerra, 2015a; Stutzer \& Frey, 2008), this is applicable to walkers and train users, whose well-being appears to be sensitive to the effects of long trips.

Regarding social exclusion, the difference for travel times between the most satisfied and the least satisfied individuals can be observed in Figure 10 . Statistically significant differences were found in safety (SE1, $p=0.098$; SE2, $p=0.092$ ), health (SE3, $p=0.014$, SE4, $p=0.017$; SE5, $p=0.055)$, accessibility (SE16, $p<0.000$ ), and social support (SE20, $p=0.048$, SE21, $p=0.018$ ).

For lifestyle health habits, in Figure 11, the difference of average travel times between students who consider them very important and "not very" important can be observed. Significant results were found for breakfast, sleep, eating balanced food and not smoking (LH1, $p=0.001$; LH2, $p=0.005$; LH3, $p=0.001$; LH4, $p=0.046)$.

Table 6. Happiness by employed travel modes.

\begin{tabular}{lllllll}
\hline & Travel time & Walk & Bicycle & Train & Bus & Car \\
\hline $\begin{array}{l}\text { Average Happiness score } \\
\text { (SD) }\end{array}$ & & 7.49 & 7.66 & 7.22 & 7.30 & 7.33 \\
\hline Pearson Correlation & & $(2.06)$ & $(2.08)$ & $(2.29)$ & $(2.18)$ & $(2.23)$ \\
Time by mode (in mins.) & $-\mathbf{0 . 1 0 3 * * *}$ & $-\mathbf{0 . 1 1 3 * * *}$ & 0.020 & $-\mathbf{0 . 0 8 6 * * *}$ & -0.020 & -0.018 \\
p-value & $\mathbf{0 . 0 0 1}$ & $\mathbf{0 . 0 0 0}$ & .529 & $\mathbf{0 . 0 0 6}$ & .529 & .577 \\
\hline
\end{tabular}

Note: $* * *$ Significant at $99 \%$ level. 


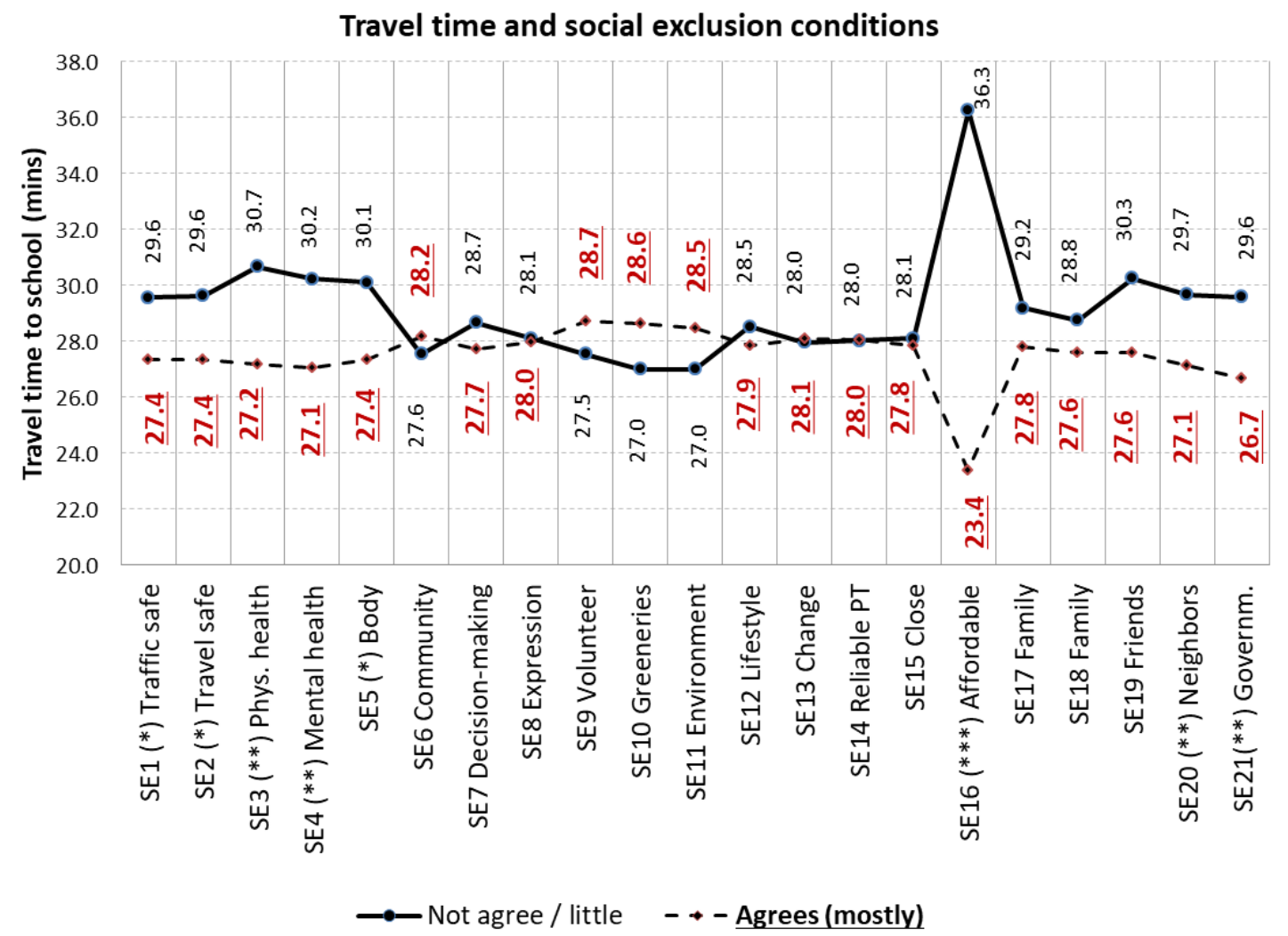

Figure 10. Comparison of travel time between different social exclusion conditions.

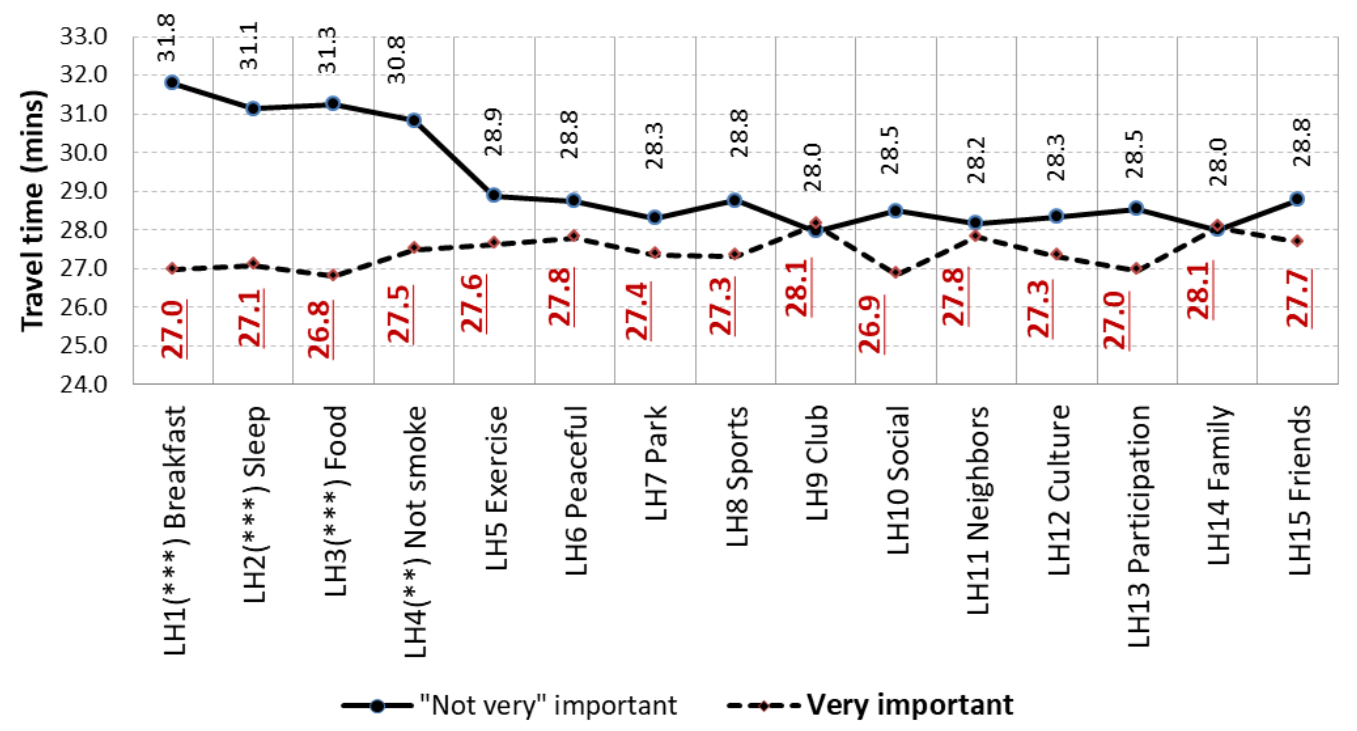

Figure 11. Comparison of travel time between healthy lifestyle propensity groups.

In Figure 12 the variation of average travel time among different levels of happiness can be observed as a complement for the information provided in Table 6 . The ANOVA test results confirm that the difference in travel time among levels of happiness is significant $(F=4.19, p$ $=0.015$ ), and one can observe how higher levels of happiness are clearly associated with shorter travel times to school. Commonly, people who spend more time commuting suffer lower well-being (Stutzer \& Frey, 2008) and may have a poorer emotional condition (Morris \& Guerra, 2015a; Olsson, Gärling, Ettema, Friman, \& Fujii, 2013).

Finally, the percentage of individuals with the most favorable well-being condition ("mostly agree/agree" for SE variables and "very important" for LH variables) between users and non-users of the different travel modes is compared. Thus, the percentage of respondents who have the most favorable well-being condition within 
Average travel time to school (in mins) by happiness level

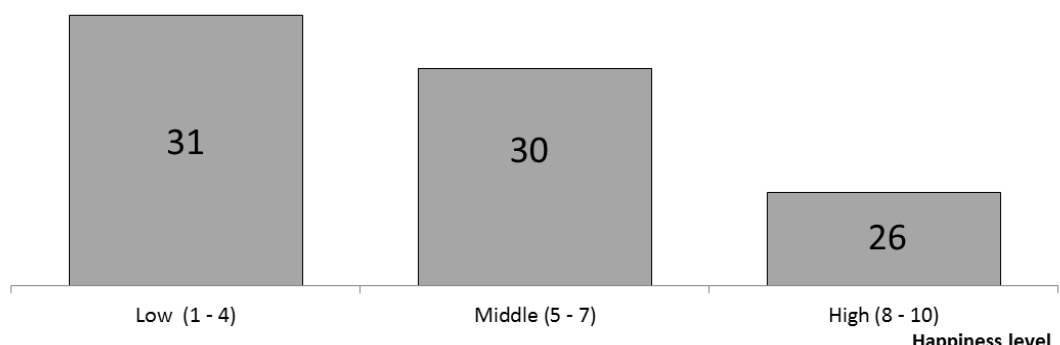

Figure 12. Happiness level and average travel time to school (in mins.) (lowest category score-highest category scoreumber of respondents in the category).

users of each travel mode (a), the percentage of respondents who have the most favorable well-being condition within non-users of each travel mode (b), F-value (c) and $p$-value (d) respectively are shown within parentheses in Table 7. For example, $71.8 \%$ of bus users often access green spaces and natural environment (SE10) whereas $62.3 \%$ of bus non-users do (see Table 6 ). If value a) is greater than b) for a well-being indicator, we place the indicator in the column "favorable effects"; otherwise, we place the indicator in the "unfavorable effects" column. In addition, well-being indicators without statistically significant differences were intentionally omitted in Table 7.

The favorable effects of cycling for students' wellbeing can be easily noted in Table 7. On the other hand, students who depend on the use of cars or buses for schooling tend to experience less satisfaction regarding well-being issues. However, the well-being of walkers and train users is more sensitive to the effects of trip duration, which cannot be observed for trips by bicycle, train, and bus. Other studies also find that people who walk and cycle tend to be more content than other commuters, such as train riders (Japan Guide, 2000). Other studies have also mentioned the positive effects of cycling on well-being (Morris \& Guerra, 2015b; St-Louis, Manaugh, van Lierop, \& El-Geneidy, 2014) as well as how car and bus users are less satisfied in comparison (StLouis et al., 2014).

\section{Discussion and Conclusions}

According to our results, it was possible to confirm links between transport disadvantage conditions and wellbeing. More specifically, living in a depopulating area, having long home-school trips, and depending on public transport (more specifically bus) are conditions of transport disadvantage that have negative implications to high school students' well-being. The longest travel times to school correspond to public transport users (bus and train) whereas the shortest travel times correspond to non-motorized modes (walk and bicycle).

The negative influence of living in a depopulating area on well-being has been evidenced for the case of Hiroshima prefecture through our results. Therefore, liv- ing in a rural depopulating area can be considered as a situation of transport disadvantage. In general terms, high-school students in rural areas tend to have slightly lower happiness scores as well as a lower propensity to keep good lifestyle habits than students in sub-urban areas. As for social exclusion related issues, aspects such as health, participation, accessibility, and social support negatively affect students in depopulating areas more than in non-depopulating areas. Volunteering and enjoyment of natural lifestyle are things that tend to be more valued among high school students in rural areas though. De Vos et al. (2013) argue that there is a direct relation between subjectively experienced well-being and residential location which may offset many of the travel related well-being benefits of high-density locations; this study contributes to support that statement. However, living in a particular area involves a range of other factors that need to be considered in order to observe the net effect of commuting on well-being (Dolan et al., 2008).

The negative effects of long trips on well-being are reflected specially in aspects such as safety, health, social support from neighbors and community, and personal indoor life habits (breakfast, sleep, balanced nutrition, not smoking). A better understanding of this phenomenon is necessary to help commuters increase their individual well-being (Olsson et al., 2013; Stutzer \& Frey, 2008). Also, we considered travel time to school and living in a depopulating area separately for analysis effects, but actually the built environment only has indirect effects through influencing commuting characteristics (Ye \& Titheridge, 2017). Our results confirm these influencing effects. For instance, the use of bus and car for schooling negatively affect students' well-being, but it cannot be considered negative per se. The increased dependence on car and bus associated to living in a depopulating area contribute to better explain these results.

It could be argued that bicycle users have more autonomy and flexibility for their trips, apart from shorter travel times, something that cannot be said of bus users. There would be restrictions for doing other out-of-school activities, which are an important part of building social capital and thus an important contribution to wellbeing. For our case study, we can confirm the depen- 
Table 7. Effects on well-being by use of different travel modes.

\begin{tabular}{|c|c|c|}
\hline & Favorable effects & Unfavorable effects \\
\hline Walk & SE16 Affordable $(\mathbf{9 1 . 4 \% , 6 1 . 3 \% , 3 4 . 3 8 , < 0 . 0 0 1 )}$ & $\begin{array}{l}\text { SE6 Community }(\mathbf{6 8 . 8 \%}, 76.5 \%, 2.73,0.099) \text {, } \\
\text { SE11 Environment }(\mathbf{5 4 . 8 \%}, 71.1 \%, 10.65,0.001)\end{array}$ \\
\hline Cycling & 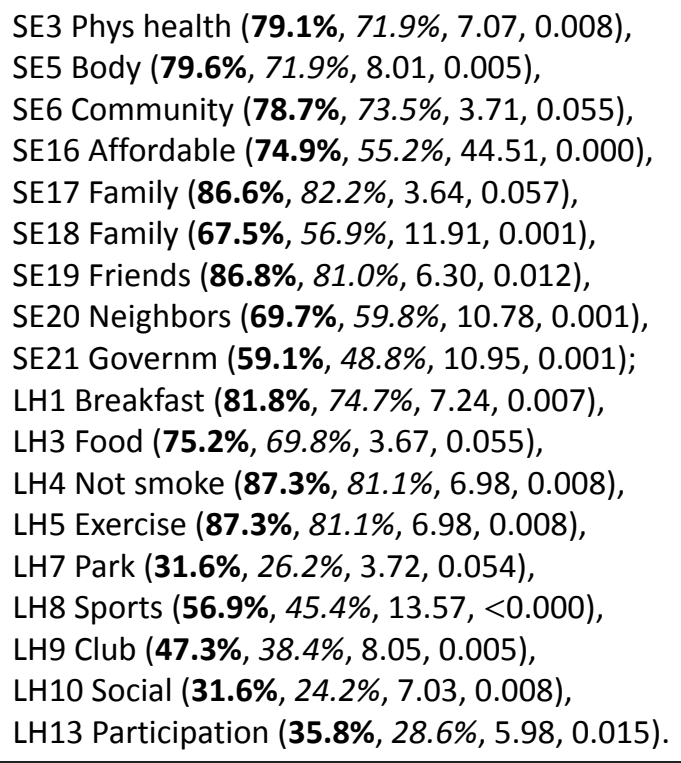 & \\
\hline Train & $\begin{array}{l}\text { SE14 Reliable PT }(86.7 \%, 78.7 \%, 6.75,0.010) \text {, } \\
\text { SE15 Close }(32.9 \%, 24.3 \%, 6.38,0.012)\end{array}$ & 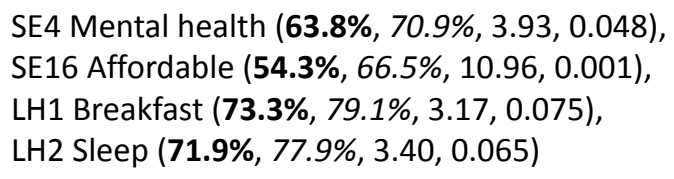 \\
\hline Bus & SE10 Greeneries $(\mathbf{7 1 . 8 \%}, 62.3 \%, 4.82,0.028)$ & 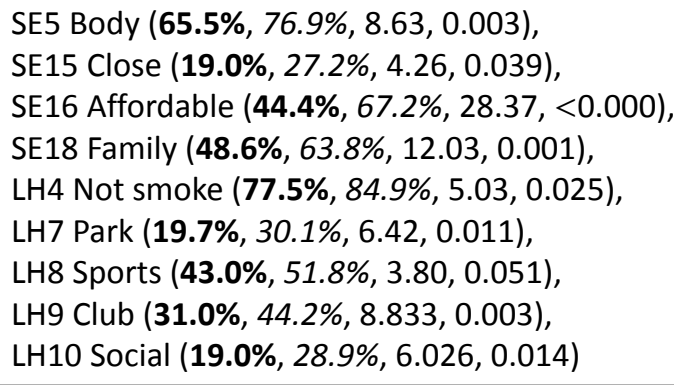 \\
\hline Car & & 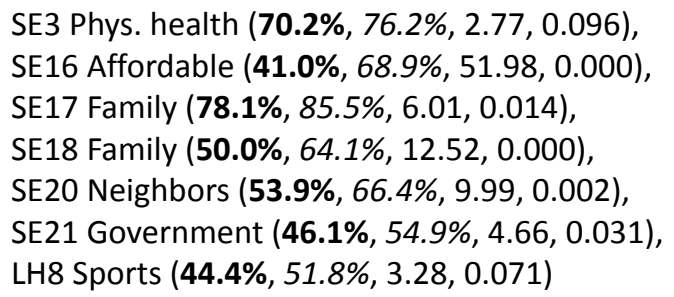 \\
\hline
\end{tabular}

dence on bus as another situation of transport disadvantage. In this regard, Morris and Guerra (2015a) argue that long trips significantly degrade the mood of bus riders. Therefore, special attention should be paid to the flexibility, accessibility, and affordability of public transport services for high school students, aspects that have been proven very sensitive and influential for a better wellbeing condition.

For future studies, based on more detailed geographical analysis by using post-code and more detailed landrelated attributes, the effects of urban landscape features on well-being could be further clarified. Similarly important, it is necessary to understand the manner in which young people interact with others and the built environment. In other words, clarifying which of the distinctive features of urban and rural environments affect the well-being of young people based on necessities and expectations at both individual and group levels. Further research should also consider the interdependence of mode use, travel-related attitudes, and travel satisfaction (De Vos, Mokhtarian, Schwanen, Van Acker, \& Witlox, 2016), as well as their joint contribution to wellbeing. These aspects, related to the daily travel experience, were not directly measured in this study, but it is 
undoubtedly an important aspect of modern life (Stutzer \& Frey, 2008) that affects people's well-being anywhere; although differently according to the residential location.

\section{Acknowledgements}

This study was supported by the Grants-in-Aid for Scientific Research (A), Japan Society for the Promotion of Science (JSPS) for the project titled "Interdisciplinary Research on Policies Promoting Young People's Migration to and Permanent Residence in Local Cities" (Principal researcher: Junyi Zhang, Hiroshima University; 15H02271), and the TAOYAKA Program for Creating a Flexible, Enduring, Peaceful Society, Hiroshima University, Program for Leading Graduate Schools, JSPS (April 2013).

\section{Conflict of Interests}

The authors declare no conflict of interests.

\section{References}

Abe, A. K. (2010). Social exclusion and earlier disadvantages: An empirical study of poverty and social exclusion in Japan. Social Science Japan Journal, 1, 5-30.

Abe, A. K. (2012). Poverty and social exclusion of women in Japan. Japanese Journal of Social Security Policy, 9(1), 61-82.

Brereton, F., Clinch, P., \& Ferreira, S. (2008). Happiness, geography and the environment. Ecological Economics, 65(2), 386-396.

Broberg, A., \& Sarjala, S. (2015). School travel mode choice and the characteristics of the urban built environment: The case of Helsinki, Finland. Transport policy, 37, 1-10.

CBS News. (2015). In Japan, first graders travel solo to school on the train. Retrieved from http://www.cbs news.com/news/japanese-young-children-solo-com mute-subway-school

De Vos, J., Mokhtarian, P. L., Schwanen, T., Van Acker, V., \& Witlox, F. (2016). Travel mode choice and travel satisfaction: Bridging the gap between decision utility and experienced utility. Transportation, 43(5), 771-796.

De Vos, J., Schwanen, T., Van Acker, V., \& Witlox, F. (2013). Travel and subjective well-being: A focus on findings, methods and future research needs. Transport Reviews, 33(4), 421-442.

De Vos, J., Schwanen, T., Van Acker, V., \& Witlox, F. (2015). How satisfying is the Scale for Travel Satisfaction. Transportation Research Part F, 29, 121-130.

Delbosc, A., \& Currie, G. (2011). The spatial context of transport disadvantage, social exclusion and well-being. Journal of Transport Geography, 19(6), 1130-1137.

Dodge, R., Daly, A. P., Huyton, J., \& Sanders, L. D. (2012). The challenge of defining wellbeing. International Journal of Wellbeing, 2(3).
Dolan, P., Peasgood, T., \& White, D. (2008). Do we really know what makes us happy a review of the literature on the factors associated with subjective well-being? Journal of Economic Psychology, 29(1), 94-122.

Ettema, D., Gärling, T., Olsson, L. E., \& Friman, M. (2010). Out-of-home activities, daily travel, and subjective well-being. Transportation Research Part A, 44(9), 723-732.

Guo, C. (2013). The busy life of a student studying in japan. Greenheart travel. Retrieved from https://greenhearttravel.org/high-school-japan/thebusy-life-of-a-student-studying-in-japan

Herwangi, Y., Pradono, P., Syabri, I., \& Kustiwan, I. (2015). Making the connection between transport disadvantage and motorcycle usage of low-income people in Yogyakarta urbanized area, Indonesia. Journal of the Eastern Asia Society for Transportation Studies, 11, 90-109.

Hodgson, S., Namdeo, A., Araujo-Soares, V., \& PlessMulloli, T. (2012). Towards an interdisciplinary science of transport and health: A case study on school travel. Journal of Transport Geography, 21, 70-79.

Honda, M., Genba, M., Kawakami, J., \& Nishizono-Maher, A. (2008). A sleep and life-style survey of Japanese high school boys: Factors associated with frequent exposure to bright nocturnal light. Sleep and Biological Rhythms, 6(2), 110-119.

Ichikawa, M., \& Nakahara, S. (2007). School regulations governing bicycle helmet use and head injuries among Japanese junior high school students. Accident Analysis \& Prevention, 39(3), 469-474.

Japan Guide. (2000). Commuting. Japan-Guide.com. Retrieved from http://www.japan-guide.com/topic/ 0011.html

Johnson, M. L., \& Johnson, J. R. (1996). Daily life in Japanese high schools. Eric Digest. Retrieved from https://www.ericdigests.org/1997-4/daily.htm

Kawano, K. (2016). Preparing your child to walk to school in Japan without you. Savvy Tokyo. Retrieved from https://savvytokyo.com/preparing-your-child-to-walk -to-school-in-japan-without-you

Kenyon, S., Lyons, G., \& Rafferty, J. (2002). Transport and social exclusion: Investigating the possibility of promoting inclusion through virtual mobility. Journal of Transport Geography, 10(3), 207-219.

Kidd, B. (2013). Walking and cycling to school in japan. Tokyo by bike. Retrieved from http://www.tokyo bybike.com/2013/02/walking-and-cycling-to-schoolin-japan.html

Lucas, K. (2011). Making the connections between transport disadvantage and the social exclusion of low income populations in the Tshwane Region of South Africa. Journal of Transport Geography, 19(6), 1320-1334.

Lucas, K. (2012). Transport and social exclusion: Where are we now? Transport Policy, 20, 105-113.

Mackett, R. L., \& Paskins, J. (2008). Children's physical activity: The contribution of playing and walking. Chil- 
dren \& Society, 22(5), 345-357.

Mori, N., Armada, F., \& Willcox, D. C. (2012). Walking to school in Japan and childhood obesity prevention: New lessons from an old policy. American Journal of Public Health, 102(11), 2068-2073.

Morris, E. A., \& Guerra, E. (2015a). Are we there yet? Trip duration and mood during travel. Transportation Research Part $F, 33,38-47$.

Morris, E. A., \& Guerra, E. (2015b). Mood and mode: does how we travel affect how we feel? Transportation, 42(1), 25-43.

Murtagh, S., Rowe, D. A., Elliott, M. A., McMinn, D., \& Nelson, N. M. (2012). Predicting active school travel: The role of planned behavior and habit strength. International Journal of Behavioral Nutrition and Physical Activity, 9(1), 65.

NIER. (2012). Education in remote and isolated areas in Japan. National Institute for Educational Policy Research. Retrieved from https://www.nier.go.jp/ English/educationjapan/pdf/201209remote.pdf

NILS. (2017). What is it like to commute to school in Japan? NILS Fukuoka Times. Retrieved from http:// www.ulearnjapanese.com/fukuoka-times/commut ing-to-school-in-japan

Nomoto, M., Hara, A., \& Kikuchi, K. (2015). Effects of longtime commuting and long-hour working on lifestyle and mental health among school teachers in Tokyo, Japan. Journal of Human Ergology, 44(1), 1-9.

Oglivie, D., Egan, M., Hamilton, V., \& Petticrew, M. (2004). Promoting walking and cycling as an alternative to using cars: Systematic Review. BMJ, 329(7469), 763.

Olsson, L. E., Gärling, T., Ettema, D., Friman, M., \& Fujii, S. (2013). Happiness and satisfaction with work commute. Social Indicators Research, 111(1), 255-263.

Perez-Barbosa, D., \& Zhang, J. (forthcoming). Future intention of young Japanese in the context of rural depopulation. Journal of the Eastern Asia Society for Transportation Studies.

Pont, K., Ziviani, J., Wadley, D., \& Abbott, R. (2011). The Model of Children's Active Travel (M-CAT): A conceptual framework for examining factors influencing children's active travel. Australian Occupational Therapy Journal, 58(3), 138-144.

Rosier, K., \& McDonald, M. (2011). The relationship between transport and disadvantage in Australia. Melbourne: Australian Institute of Family Studies.

Schwanen, T., Lucas, K., Akyelken, N., Solsona, D. C., Carrasco, J. A., \& Neutens, T. (2015). Rethinking the links between social exclusion and transport disadvantage through the lens of social capital. Transportation Research Part A: Policy and Practice, 74, 123-135.

Schwanen, T., \& Wang, D. (2014). Well-being, context, and everyday activities in space and time. Annals of the Association of American Geographers, 104(4), 833-851.

St-Louis, E., Manaugh, K., van Lierop, D., \& El-Geneidy, A. (2014). The happy commuter: A comparison of commuter satisfaction across modes. Transportation Research Part F, 26, 160-170.

Stutzer, A., \& Frey, B. S. (2008). Stress that doesn't pay: The commuting paradox. Scandinavian Journal of Economics, 110(2), 339-366.

Tagaya, H., Uchiyama, M., Ohida, T., Kamei, Y., Shibui, K., Ozaki, A., . . . Takahashi, K. (2004). Sleep habits and factors associated with short sleep duration among Japanese high-school students: A community study. Sleep and Biological Rhythms, 2(1), 57-64.

Takakura, M., Nagayama, T., Sakihara, S., \& Willcox, C. (2001). Patterns of health-risk behavior among Japanese high school students. Journal of School Health, 71(1), 23-29.

Takakura, M., \& Sakihara, S. (2001). Psychosocial correlates of depressive symptoms among Japanese high school students. Journal of Adolescent Health, 28(1), 82-89.

Timperio, A., Ball, K., Salmon, J., Roberts, R., Giles-Corti, B., Simmons, D., . . . Crawford, D. (2006). Personal, family, social, and environmental correlates of active commuting to school. American Journal of Preventive Medicine, 30(1), 45-51.

Trapp, G. S., Giles-Corti, B., Christian, H. E., Bulsara, M., Timperio, A. F., McCormack, G. R., \& Villaneuva, K. P. (2011). On your bike! A cross-sectional study of the individual, social and environmental correlates of cycling to school. International Journal of Behavioral Nutrition and Physical Activity, 8(1), 123.

Ye, R., \& Titheridge, H. (2017). Satisfaction with the commute: The role of travel mode choice, built environment and attitudes. Transportation Research Part $D$, 52B, 535-547.

Zhang, J., Chikaraishi, M., Xiong, Y., Jiang, Y., \& Seya, H. (2016). Young people's life choices and travel behavior: State-of-the-art and future perspectives. A discussion paper for the Workshop "Young People's Life Choices and Travel Behavior" at the 95th Annual Meeting of Transportation Research Board, Washington D.C., 10-14 January 2016.

\section{About the Authors}

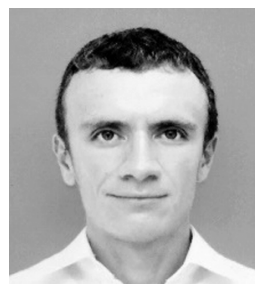

David Perez Barbosa (D. Eng.) is a researcher at Hiroshima University. His research areas and interests include transport-based social exclusion, transport disadvantage, well-being, health-related quality of life, active travel modes, road safety and the identification of vulnerable groups. He is particularly interested in the promotion of non-motorized transport as an essential part of urban development agendas, considering its contributions for improving several aspects of individual and societal well-being. 


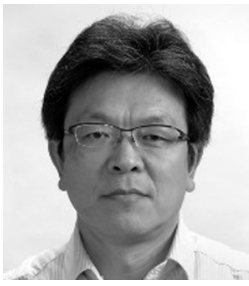

Junyi Zhang's research fields include urban and regional planning, transportation planning, traffic engineering, environment and energy policies, tourism policy, and health policy. He has developed various methodologies and applied them to analyze various issues related to the above fields from an interdisciplinary perspective, mainly based on behavioral and systematic approaches. In recent years, he has been especially promoting the life-oriented approach for cross-sectoral policies. He has published more than 370 peer-reviewed academic papers. 